\title{
Nonlinear Friction Modeling and Compensation for Precision Control of a Mechanical Feed-Drive System
}

\author{
Ba Dinh Bui, Naoki Uchiyama* and Shigenori Sano \\ Department of Mechanical Engineering, Toyohashi University of Technology, \\ 1-1 Hibarigaoka, Tempaku, Toyohashi, Aichi 441-8580, Japan
}

(Received February 16, 2015; accepted August 7, 2015)

Key words: feed-drive system, friction compensation, contouring control, disturbance observer, high-precision control

Friction exists in mechanical systems, such as machine-tool feed drives, and causes undesired position tracking errors. The most difficult problem in friction compensation is nonlinear friction during changes in motion direction or in low velocity regions causing significant tracking errors. Many static and dynamic friction models have been proposed to compensate for frictional effects to reduce the tracking error in the desired trajectory, in particular, in low velocity regions. Although recently developed dynamic friction models consider the pre-sliding regime friction behavior and friction properties in regions of near-zero velocity, these existing friction models consider only limited sources of friction. In this paper, we present a new friction model that considers many friction sources with complicated and nonlinear properties not only in near-zero velocity regions but also in higher velocity regions. In addition, we present a controller design that includes a feed forward compensation term with the proposed friction model and a disturbance observer. Experiments were conducted to compare the control performance between the proposed and conventional friction models. The proposed controller largely improved the control performance, reducing the maximum contouring error to less than 1.6 $\mu \mathrm{m}$.

\section{Introduction}

Friction in mechanical systems such as machine-tool feed drives is the main factor reducing tracking accuracy and machining surface quality. Therefore, friction compensation is generally required in controller design for high precision motion. A controller that compensates for friction without using high-gain control loops inherently requires a suitable friction model: hence, this controller is called a model-based friction compensator. A good friction model is also necessary to analyze the stability, predict the friction behavior, and perform simulations.

${ }^{*}$ Corresponding author: e-mail: uchiyama@tut.jp 
Many simple and advanced friction models have been proposed in the literature. Most existing model-based friction compensators use conventional static friction models that describe the static map between velocity and friction force. ${ }^{(1)}$ The conventional static friction model does not describe friction in the pre-sliding regime and is insufficient to represent the friction behavior at very low velocities. Dynamic friction models have been proposed to compensate for these shortcomings. ${ }^{(2)}$ The LuGre friction model is widely applied owing to its simplicity and relatively good performance. ${ }^{(3)}$ Swevers et al. have improved the LuGre model, resulting in the Leuven integrated friction model, ${ }^{(4)}$ which has been further modified by Lampaert et al.(5) Recently, Al-Bender et al. developed the so-called generalized Maxwell-slip (GMS) friction model.(6)

Various model-based and non-model-based friction compensation schemes have been proposed thus far. Armstrong-Helouvry et al. have carried out a survey on friction models and compensation methods for controlling machines with friction. ${ }^{(7)}$ Canudas de Wit and Lischinsky utilized their LuGre friction model for adaptive friction compensation. ${ }^{(8)}$ Tjahjowidodo et al. have shown that a Maxwell-slip-model-based nonlinear gain scheduling controller yields a fast response and a low steady-state error for friction compensation in electromechanical systems. ${ }^{(9)}$ Tung et al. applied a nonmodel-based friction compensation approach in the form of a repetitive controller and demonstrated improved tracking performance and quadrant glitch compensation. ${ }^{(10)}$ Lampaert et al. compared model-based and non-model-based friction compensations for a tracking application on a dedicated test setup (a tribometer) and concluded that a combination of GMS friction model-based feed forward and disturbance observers yielded the best performance. ${ }^{(11)}$

Regarding machine-tool feed drives, Erkorkmaz and Altintas proposed an unbias identification method and proved the effectiveness of static friction compensation. ${ }^{(12)}$ Jamaludin et al. used a dynamic friction model (GMS friction model) for friction compensation techniques and evaluated it experimentally on a linear-drive XY table. ${ }^{(13,14)}$ The GMS friction model or other dynamic friction models provide better results than the conventional static friction model only in the low velocity region.

In this paper, we focus on a static friction model and assume that nonlinear friction phenomena appear both in very low and high velocity regions. We propose a new nonlinear friction model that includes a model of nominal linear frictions (e.g., Coulomb and viscous frictions) and a number of nonlinear friction sources represented by Gaussian functions. In addition, we present a controller design that consists of a feed forward compensation term with the proposed friction model and a disturbance observer. Experiments were conducted to compare the control performance between the proposed and conventional static friction models. The proposed controller largely improved the control performance, reducing the maximum contouring error to less than $1.6 \mu \mathrm{m}$.

\section{Conventional and Proposed Static Friction Models}

The conventional static friction model describes the steady-state friction behavior, which depends on the sliding velocity $v$. The model incorporates the Coulomb, viscous, and Stribeck frictions as follows: 


$$
F_{\mathrm{f}}(v)=\left[\alpha_{0}+\left(\alpha_{1}-\alpha_{0}\right) e^{-\left(v v_{0}^{-1}\right)^{\delta}}\right] \operatorname{sgn}(v)+\alpha_{2} v,
$$

where $F_{\mathrm{f}}, v, \alpha_{0}, \alpha_{1}$, and $\alpha_{2}$ are scalar and represent the friction force, motion velocity, Coulomb force, static friction, and viscous friction coefficients, respectively. The Stribeck friction model parameters are the Stribeck velocity $v_{0}$ and superscript $\delta$.

Although the friction model in eq. (1) is widely used, it considers only three terms with fixed structures, and therefore its prediction of friction behavior is limited. In this paper, we present a new friction model that considers a number of friction sources with complicated and nonlinear properties as follows:

$$
F_{\mathrm{f}}(v)=\eta_{0} \operatorname{sgn}(v)+\eta_{1} v+\sum_{i=1}^{n} g_{i \mathrm{a}} \exp \left[-\left(\frac{v-g_{i \mathrm{~b}}}{g_{i \mathrm{c}}}\right)^{2}\right],
$$

where $\eta_{0}(>0)$ and $\eta_{1}(>0)$ are the nominal Coulomb force and viscous friction coefficients of the feed drive, respectively. The nonlinear properties of the friction are defined by the sum of $n$ Gaussian equations in which $g_{i a}, g_{i b}$, and $g_{i c}$ denote the height of the Gaussian curve's peak, the position of the center of the peak, and the width of the curve, respectively. The proposed model can include many nonlinear properties by increasing the number $n$; thus, we believe that it can be applied to various frictional properties. The limitation of this model is that it does not include dynamic properties as in ref. 3. However, in our study, the dynamic properties of the object were not seen in the experiment such that the proposed model would be effective for the feed-drive system. In particular, the proposed model is effective for the object with many friction sources such as a sliding guide, a ball screw and a motor gear.

\section{Identification of Friction Models}

\subsection{Friction observation}

To identify the friction model parameters in eqs. (1) and (2), we first employed a proportional-derivative controller (PD controller) and a disturbance observer to obtain the friction value. The typical mechanical dynamics is represented as follows:

$$
m \ddot{\boldsymbol{x}}+\boldsymbol{d}=\boldsymbol{f},
$$

where $m(>0), \boldsymbol{x}, \boldsymbol{d}$, and $\boldsymbol{f}$ are the table mass, position, friction force with disturbance, and driving force (control input), respectively.

A PD controller with a disturbance observer was designed on the basis of the dynamics in eq. (3) as follows:

$$
\begin{gathered}
\boldsymbol{f}=\bar{m}\left(\ddot{\boldsymbol{r}}-k_{\mathrm{p}} \dot{\boldsymbol{e}}-k_{\mathrm{d}} \boldsymbol{e}\right)+\hat{\boldsymbol{d}}, \\
\boldsymbol{e}=\boldsymbol{x}-\boldsymbol{r},
\end{gathered}
$$


where $\bar{m}, k_{\mathrm{p}}, k_{\mathrm{d}}, \boldsymbol{e}$, and $\boldsymbol{r}$ are the nominal mass, proportional gain, derivative gain, tracking error, and reference position, respectively. The friction force $\boldsymbol{d}$ was estimated as $\hat{\boldsymbol{d}}$ by a disturbance observer ${ }^{(15)}$ as follows:

$$
\begin{gathered}
\dot{\hat{\boldsymbol{v}}}=\frac{1}{\bar{m}}(\boldsymbol{f}-\hat{\boldsymbol{d}})+k_{\mathrm{ev}}(\hat{\boldsymbol{v}}-\dot{\boldsymbol{r}}), \\
\dot{\hat{\boldsymbol{d}}}=k_{\mathrm{ed}}(\hat{\boldsymbol{v}}-\dot{\boldsymbol{r}}),
\end{gathered}
$$

where $\hat{\boldsymbol{v}}$ is the estimated velocity and $k_{\mathrm{ev}}$ and $k_{\mathrm{ed}}$ are disturbance observer gains.

\subsection{Experimental setup}

The parameters of the friction model in eqs. (1) and (2) were identified experimentally. The experimental setup was a typical biaxial feed-drive system shown in Fig. 1, which consisted of two axes driven by DC servo motors coupled to drive two ball screws. We assumed that the friction on each feed drive was the sum of many friction sources such as ball bearings, gears, and ball screws and nuts. A rotary encoder whose resolution for position measurement was $0.025 \mu \mathrm{m}$ was attached to each feeddrive servomotor to measure the actual position of the feed-drive system. In the absence of a velocity sensor, the velocity signal was calculated using the numerical differentiation of the position measurement. The system was controlled by a personal computer (OS, Windows; CPU, $1 \mathrm{GHz}$ ) with a sampling time of $5 \mathrm{~ms}$. C++ language was used to write the control program. To provide a fixed sampling period in a Windows environment,

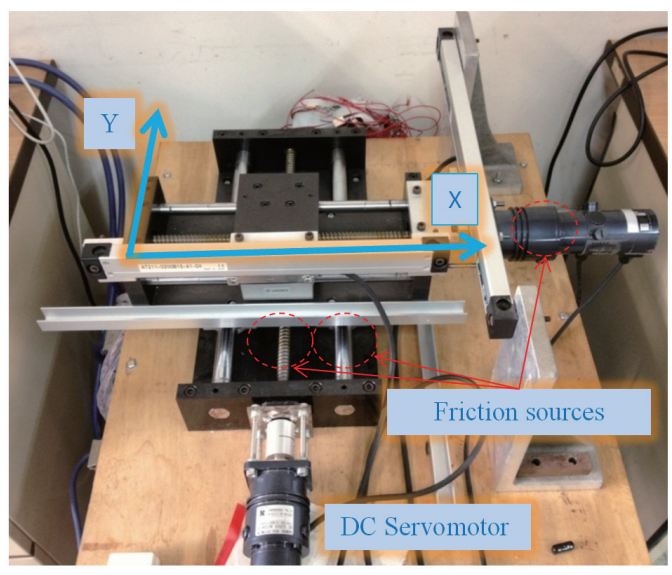

Fig. 1. (Color online) Biaxial feed-drive system. 
we employed a timer on a counter board with four channels of 24-bit up/down counters. Equivalent mass parameter values in eq. (3) for $x$ - and $y$-axes of the experimental setup were $m_{x}=57.65 \mathrm{~kg}$ and $m_{y}=58.93 \mathrm{~kg}$, respectively.

\subsection{Identification of conventional model}

When the dynamics in eq. (1) operate at a constant velocity, the driving force equals the friction force in eq. (3). Hence, constant velocity motion was enforced using a PD feed-drive controller [eq. (4)] with a disturbance observer [eq. (5)]. This experiment was repeated for constant velocities of $0.01,0.04,0.08,0.15,0.2,0.4,0.5,1.0,1.5,2.5,3.0$, 3.5, 4.0, 4.5, 5.0, 5.5, 6.0, 6.5, 7.0, 7.5, 8.0, 8.5, and $9.0 \mathrm{~mm} / \mathrm{s}$. The PD feedback gains $k_{\mathrm{p}}$ $=1600 \mathrm{~s}^{-2}$ and $k_{\mathrm{d}}=80 \mathrm{~s}^{-1}$, and the disturbance gains $k_{\mathrm{ev}}=40 \mathrm{~s}^{-1}$ and $k_{\mathrm{ed}}=20 \mathrm{kgs}^{-1}$ were assigned in the controller.

Figure 2 shows the measured and fitted static friction model represented by eq. (1). The Stribeck effect did not clearly appear in the experimental results, and it was assumed to be zero. The least-squares method was used to obtain the optimized friction model parameters. The obtained parameters were $\alpha_{0}=\alpha_{1}=1255.38 \mathrm{~N}$, and $\alpha_{2}=105.04 \mathrm{Ns} / \mathrm{mm}$ for the $x$-axis, and $\alpha_{0}=\alpha_{1}=1066.05 \mathrm{~N}$ and $\alpha_{2}=138.86 \mathrm{Ns} / \mathrm{mm}$ for the $y$-axis.

\subsection{Identification of proposed model}

Because the conventional friction model has a simple structure, it cannot describe friction well in both high and low velocity regions. To obtain friction more precisely, we identified the proposed friction model in eq. (2) from sinusoidal signal tracking results.

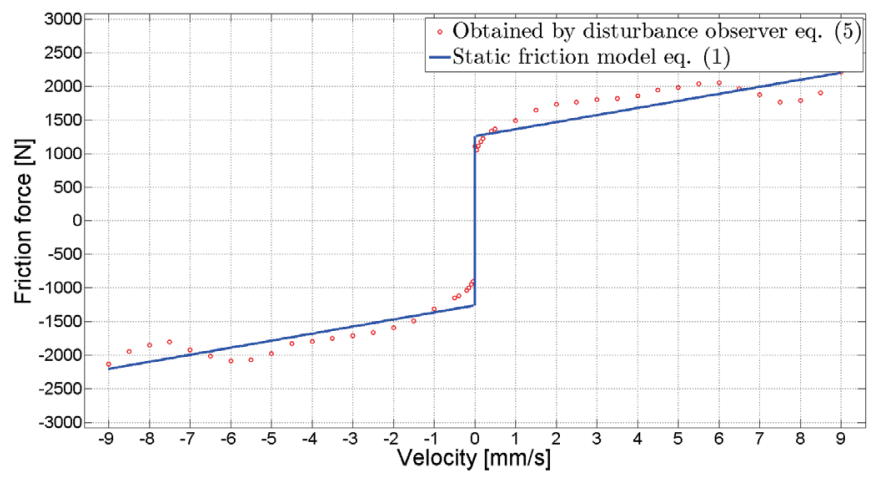

Fig. 2. (Color online) Measured and computed static friction-velocity map with a conventional model. 
A PD controller and a disturbance observer in eqs. (4) and (5) were used for this control, and driving forces were measured. Then, the friction force at each sampling time was estimated.

We explain here the method for the $x$-axis; a similar method was applied to the $y$-axis. The following sinusoidal reference was used in the identification experiments:

$$
\begin{gathered}
r=-20+20 \cos (0.475 t)(\mathrm{mm}), \\
0.0<t<\frac{4.0 \pi}{0.475}(\mathrm{~s}),
\end{gathered}
$$

where $r$ is the reference position on the $x$-axis. The reference sinusoidal signal was repeated several times to eliminate uncertainty. Controller gains for the PD controller were $k_{\mathrm{p}}=1600 \mathrm{~s}^{-2}$ and $k_{\mathrm{d}}=80 \mathrm{~s}^{-1}$, and disturbance observer gains were $k_{\mathrm{ev}}=40 \mathrm{~s}^{-1}$ and $k_{\mathrm{ed}}=20 \mathrm{kgs}^{-1}$.

Although the reference signal is well tracked in Fig. 3, a tracking error with a maximum magnitude of around $5 \mu \mathrm{m}$ still remains. The measured driving force is shown in Fig. 4, in which chattering is also visible. To avoid the effect of noise in the identification, we assumed that $\dot{r} \cong \dot{x}$ and $\ddot{r} \cong \ddot{x}$, and then from eq. (3), the disturbance force was estimated as follows:

$$
d=f-\bar{m} \ddot{r} .
$$

The fluctuating green line in Fig. 5 denotes the disturbance force obtained using eq. (7). We assumed that the estimated disturbance at $x$ comprises only friction and white noise with a zero mean value. A lower frequency filter was used to eliminate this noise and to obtain the friction as shown by the blue dotted line. From Fig. 5, we see that the actual friction force is nonlinear in both the low and high velocity regions. Therefore,

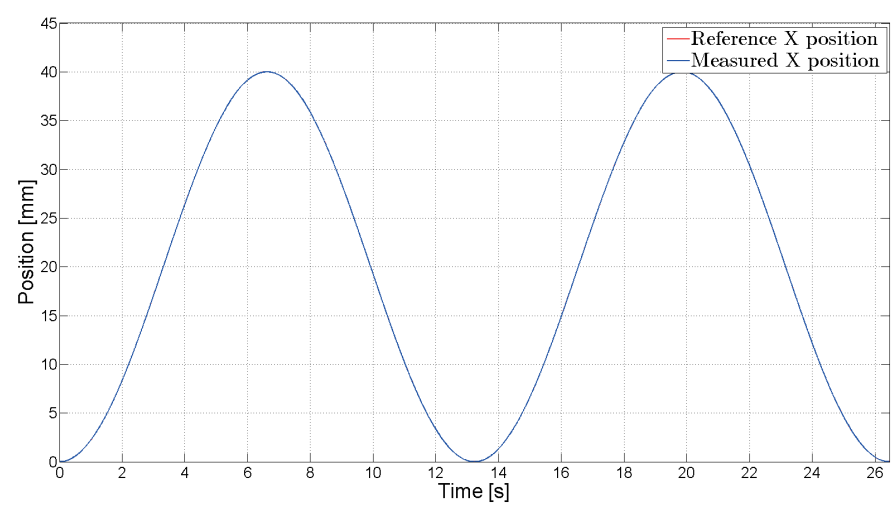

Fig. 3. (Color online) Reference and measured $x$-positions. 


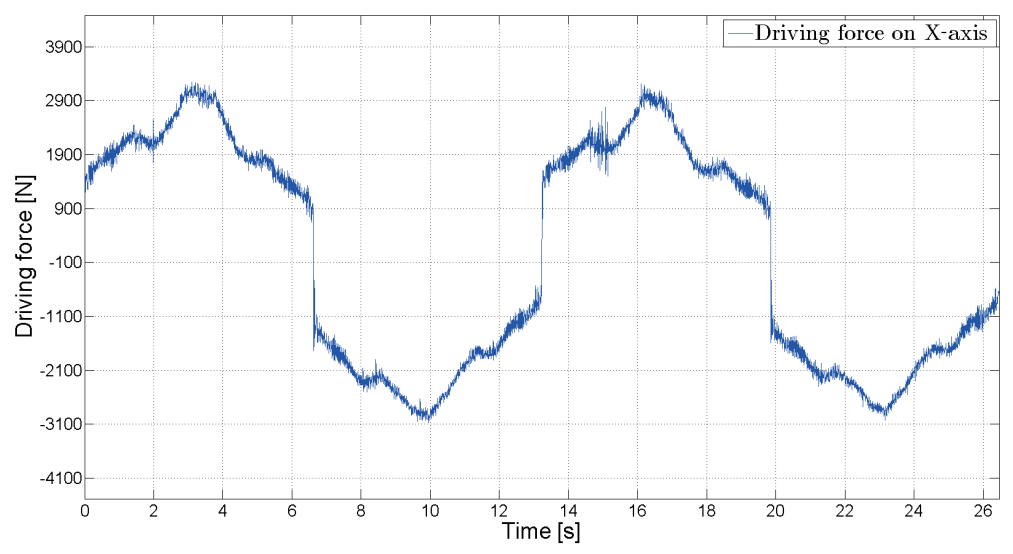

Fig. 4. (Color online) Driving force.

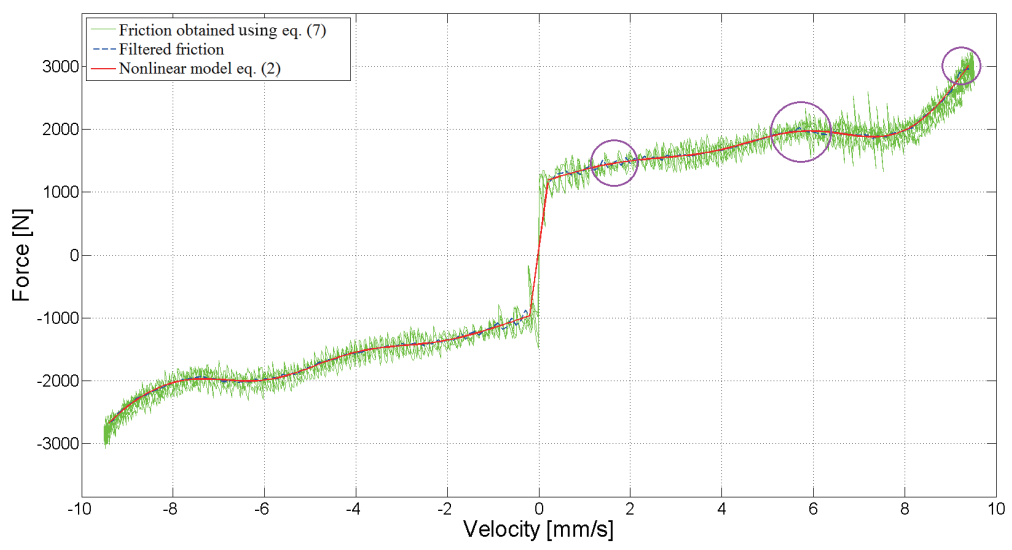

Fig. 5. (Color online) Measured and estimated frictions.

the conventional friction model was not sufficient for describing the actual friction in a feed-drive system, and the nonlinear static friction model in eq. (2) was proposed. The Gaussian function is not a unique candidate for describing nonlinear properties in Fig. 5 , and possible candidates are a sinusoidal function, a polynomial function, a spline and so on. The advantage of the Gaussian function is that frictional properties from difference sources can be added easily by changing the number $n$ in eq. (2). The number of Gaussian functions used is equal to the number of peaks of the estimated friction (circles in Fig. 5). For curve fitting in Fig. 5, the Nelder-Mead downhill simplex method ${ }^{(16)}$ was employed, and the result is represented by a red line. The parameters in eq. (2) for $x$ and $y$ are shown as estimated values in Table 1 . 
Table 1

Estimated nonlinear static friction model parameters.

\begin{tabular}{|c|c|c|c|c|c|c|c|c|c|c|c|c|}
\hline \multirow{2}{*}{$\begin{array}{l}\text { Esimated } \\
\text { parameters }\end{array}$} & \multicolumn{6}{|c|}{$x$-axis } & \multicolumn{6}{|c|}{$y$-axis } \\
\hline & \multicolumn{3}{|c|}{$\dot{x} \geq 0$} & \multicolumn{3}{|c|}{$\dot{x}<0$} & \multicolumn{3}{|c|}{$\dot{y} \geq 0$} & \multicolumn{3}{|c|}{$\dot{y}<0$} \\
\hline$\eta_{0}, \eta_{1}, n$ & 768.6 & 102.48 & 3 & -768.6 & 102.4 & 3 & 640.5 & 140.9 & 3 & -640.5 & 140.9 & 3 \\
\hline$g_{1 \mathrm{a}}, g_{1 \mathrm{~b}}, g_{1 \mathrm{c}}$ & 517.4 & 1.76 & 3.09 & -378.2 & -2.16 & 2.26 & 518.0 & 1.76 & 1.98 & -371.34 & -1.96 & 2.99 \\
\hline$g_{2 \mathrm{a}}, g_{2 \mathrm{~b}}, g_{2 \mathrm{c}}$ & 509.3 & 5.80 & 1.82 & -547.5 & -5.91 & 1.76 & 852.0 & 5.87 & 2.73 & -236.1 & -5.80 & 1.22 \\
\hline$g_{3 \mathrm{a}}, g_{3 \mathrm{~b}}, g_{3 \mathrm{c}}$ & 1995.9 & 10.66 & 1.87 & -4472 & -13.9 & 3.65 & 1059.1 & 10.2 & 1.74 & -354.97 & -9.31 & 0.47 \\
\hline
\end{tabular}

The unit for $\eta_{0}, g_{1 \mathrm{a}}, g_{2 \mathrm{a}}$, and $g_{3 \mathrm{a}}$ is $\mathrm{N}$, the unit for $\eta_{1}$ is Ns/mm, and the unit for $g_{1 \mathrm{~b}}, g_{2 \mathrm{~b}}, g_{3 \mathrm{~b}}, g_{1 \mathrm{c}}, g_{2 \mathrm{c}}$, and $g_{3 \mathrm{c}}$ is $\mathrm{mm} / \mathrm{s}$.

\section{Contouring Controller Design with Friction Compensation and Experimental Results}

\subsection{Contouring controller design}

In machining, the contour error is an importance criterion to define the quality of the machined surface. In this study, the proposed friction compensation was applied to a contouring controller. ${ }^{(17-26)}$

Figure 6 schematically explains the relationship between the tracking error in each feed-drive axis and the contour error. The coordinate $\sum_{\mathrm{w}}$, whose $x$ - and $y$-axes correspond to the feed-drive axes, is a fixed frame. The curve $\mathrm{C}$ in the figure is the desired contour curve of the point of a machined part driven by the feed-drive system. The symbol $\boldsymbol{r}=\left[r_{x}, r_{y}\right]^{T}$ is the desired position of the point of the machined part at time $t$ and is defined in $\sum_{\mathrm{w}}$. The actual position of the feed-drive system is assumed to be $\boldsymbol{q}=\left[q_{x}, q_{y}\right]^{T}$, which is also defined in $\sum_{\mathrm{w}}$ (notations have been changed from the preceding sections). The contour error is defined as the shortest distance from $q$ to the desired contour $\mathrm{C}$ and is represented by the symbol $\boldsymbol{e}_{\mathrm{c}}$; the contouring controller reduces this error. A local coordinate frame $\sum_{1}$ is also defined, its origin is at the desired position $\boldsymbol{r}$, and its two axes $T$ and $N$, are shown in the figure. The axis $T$ is in the tangential direction of $\mathrm{C}$ at $\boldsymbol{r}$, and $N$ is perpendicular to $T$ at $\boldsymbol{r}$. The tracking error vector $\boldsymbol{e}_{\mathrm{w}}$, which consists of the tracking errors in both feed-drive axes, is defined as follows:

$$
\boldsymbol{e}_{\mathrm{w}}=\left[e_{\mathrm{w} x}, e_{\mathrm{w} y}\right]^{T}=\boldsymbol{q}-\boldsymbol{r} .
$$

This error vector can be expressed with respect to $\sum_{1}$ as follows:

$$
\begin{gathered}
\boldsymbol{e}_{1}=\left[e_{1 t}, e_{1 n}\right]^{T}=\boldsymbol{R}^{T} \boldsymbol{e}_{\mathrm{w}}, \\
\boldsymbol{R}=\left[\begin{array}{cc}
\cos \theta & -\sin \theta \\
\sin \theta & \cos \theta
\end{array}\right],
\end{gathered}
$$

where the inclination $\theta$ of $\sum_{1}$ to $\sum_{\mathrm{w}}$ is shown in Fig. 6. We have defined the following improved contouring controllers where a disturbance observer and feed-forward friction 


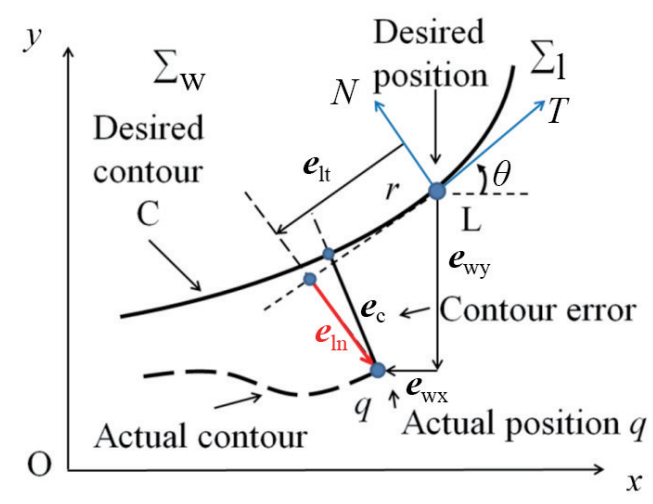

Fig. 6. (Color online) Definition of contour error.

compensation are included in the controller:(26)

$$
\begin{gathered}
\boldsymbol{F}=\boldsymbol{M}\left[\ddot{\boldsymbol{r}}-\boldsymbol{R}\left(\boldsymbol{K}_{\mathrm{vl}} \dot{\boldsymbol{e}}_{\mathrm{l}}+\boldsymbol{K}_{\mathrm{pl}} \boldsymbol{e}_{1}\right)-\ddot{\theta} \boldsymbol{I}_{\mathrm{e}} \boldsymbol{e}_{\mathrm{w}}+\dot{\theta}^{2} \boldsymbol{I} \boldsymbol{e}_{\mathrm{w}}-2 \dot{\theta} \boldsymbol{I}_{\mathrm{e}} \dot{\boldsymbol{e}}_{\mathrm{w}}\right]+\boldsymbol{D}+\boldsymbol{F}_{\mathrm{f}}, \\
\boldsymbol{I}_{\mathrm{e}}=\left[\begin{array}{cc}
0 & 1 \\
-1 & 0
\end{array}\right], \boldsymbol{F}=\left[f_{x}, f_{y}\right]^{T}, \boldsymbol{M}=\operatorname{diag}\left(m_{x}, m_{y}\right), \boldsymbol{D}=\left[d_{x}, d_{y}\right]^{T}, \\
\boldsymbol{F}_{\mathrm{f}}=\left[F_{\mathrm{f} x}, F_{\mathrm{f} y}\right]^{T}, \boldsymbol{K}_{\mathrm{vl}}=\left[k_{\mathrm{vl} t}, \boldsymbol{k}_{\mathrm{vl} n}\right]^{T}, \boldsymbol{K}_{\mathrm{pl}}=\left[k_{\mathrm{pl} t}, k_{\mathrm{pl} l}\right]^{T},
\end{gathered}
$$

where $\boldsymbol{F}, \boldsymbol{M}, \boldsymbol{I}$, and $\ddot{\boldsymbol{r}}$ are the driving force vector, table mass matrix, $2 \times 2$ identity matrix, and reference acceleration vector of the desired contour, respectively. The symbols $\boldsymbol{K}_{\mathrm{vl}}$ and $\boldsymbol{K}_{\mathrm{pl}}$ are the velocity and position feedback gain matrices, respectively. They are assumed to be diagonal matrices with positive elements. The disturbances $d_{x}$ and $d_{y}$ are estimated as follows:

$$
\begin{gathered}
\dot{\hat{q}}=\frac{1}{\overline{\bar{m}}_{1}}\left(f_{i}-F_{\mathrm{f} i}-\hat{d}_{1}\right)+k_{\mathrm{ev}}\left(\hat{\dot{q}}-\dot{r}_{1}\right), \\
\dot{\hat{d}}_{1}=k_{\mathrm{ed}}\left(\hat{\dot{q}}_{1}-\dot{r}_{1}\right), i=x, y .
\end{gathered}
$$

\subsection{Experimental conditions}

The friction compensation performance was verified on the basis of circular reference tracking control results. Most studies use circular control because of its simplicity in estimating the contour error and in calculating the reference velocity and acceleration. ${ }^{(26)}$ The maximum contour error, maximum quadrant glitch, root mean square contour error, and standard deviation were used to verify the friction compensation performance. Quadrant glitches occur in near-zero velocity regions in each feed-drive axis and typically demonstrate the performance in a circular tracking test of an $X Y$ feed-drive table. 
The friction compensation performance was compared for the following different controller configurations (all the controllers are based on the PD control):

A. no friction compensation,

B. conventional feed-forward friction compensation,

C. proposed nonlinear feed-forward friction compensation,

D. disturbance observer,

E. conventional feed-forward friction compensation and disturbance observer, and

F. proposed nonlinear feed-forward friction compensation and disturbance observer.

For comparison, the same PD controller gains are used in all controllers: $\boldsymbol{K}_{\mathrm{vl}}=[40$ $\left.\mathrm{s}^{-1}, 60 \mathrm{~s}^{-1}\right]$ and $\boldsymbol{K}_{\mathrm{pl}}=\left[1600 \mathrm{~s}^{-2}, 3600 \mathrm{~s}^{-2}\right]$ for both low and high velocity regions. The low velocity experiment used a sinusoidal reference with an amplitude of $10 \mathrm{~mm}$ and a frequency of $0.3 \mathrm{rad} / \mathrm{s}$, resulting in a feed-drive velocity of $3 \mathrm{~mm} / \mathrm{s}$, which was applied to each axis.

$$
\begin{gathered}
r_{x}=10 \cos (0.3 t)(\mathrm{mm}) \\
r_{y}=10 \sin (0.3 t)(\mathrm{mm}) \\
0.0<t<\frac{4.0 \pi}{0.3}(\mathrm{~s})
\end{gathered}
$$

The high velocity experiment used a sinusoidal reference with an amplitude of 20 $\mathrm{mm}$ and a frequency of $0.475 \mathrm{rad} / \mathrm{s}$, resulting in a feed-drive velocity of $9.5 \mathrm{~mm} / \mathrm{s}$, which was applied to each axis.

$$
\begin{gathered}
r_{x}=20 \cos (0.475 t)(\mathrm{mm}) \\
r_{y}=20 \sin (0.475 t)(\mathrm{mm}) \\
0.0<t<\frac{4.0 \pi}{0.475}(\mathrm{~s})
\end{gathered}
$$

\subsection{Experimental results}

Figure 7 shows the contouring error results obtained by applying controllers D-F. Table 2 shows the average results for ten trials in each controller at low velocity, and we see that the maximum contour error often occurs in the quadrants, and therefore its value equals the maximum quadrant glitch. By comparing the results in $\mathrm{B}$ and $\mathrm{C}$ where only feed-forward compensation is applied, the nonlinear static friction model shows better performance. In controller $C$, the maximum contour error decreases more than $50 \%$ in comparison with that in controller B. This means that the proposed friction model is effective for the condition (low-speed condition) different from the identification experiment condition (high-speed condition). The controller with the disturbance observer and the conventional static friction model in E provides slightly better performance than controller $\mathrm{F}$ where the maximum contour error is reduced to only 3.71 $\mu \mathrm{m}$. The difference between controllers $\mathrm{E}$ and $\mathrm{F}$ in Table 2 is due to the coupling effect between the friction model and the disturbance observer. To clarify this reason, both experimental and further theoretical analyses are required, and this will be left for future work. 

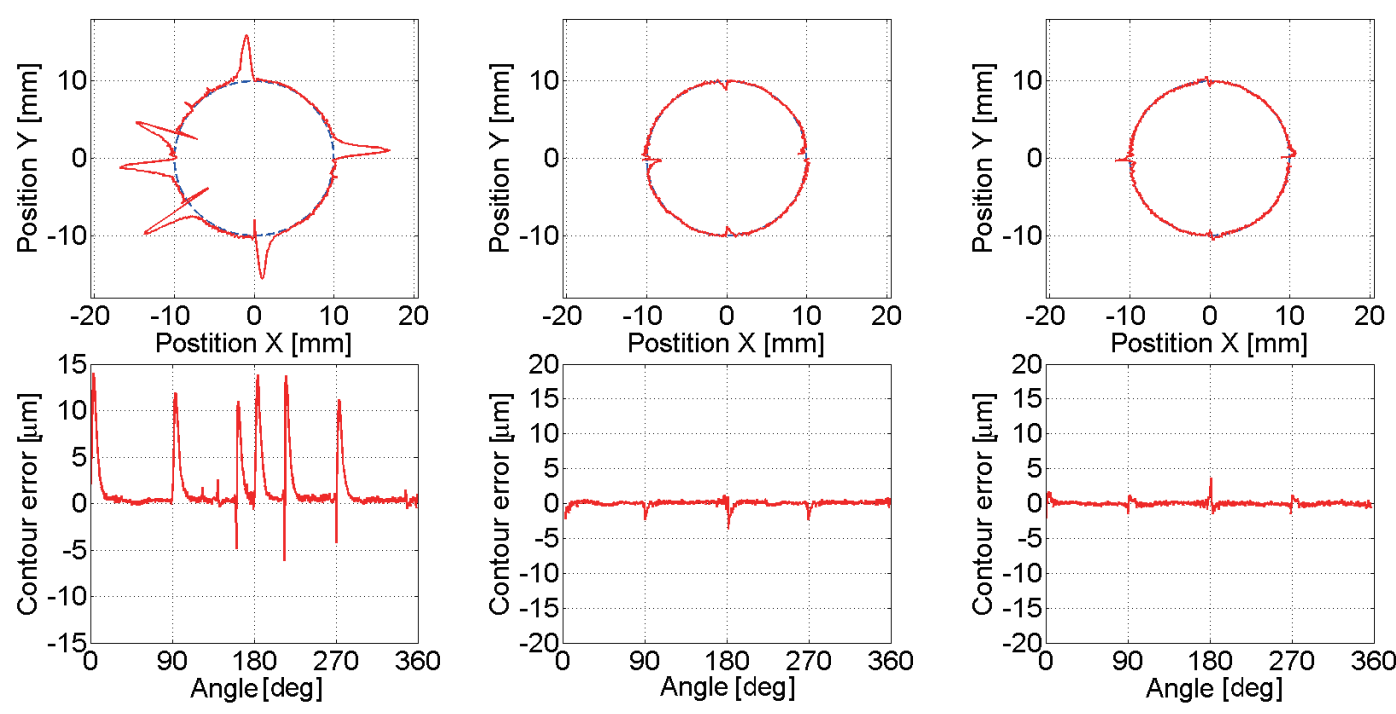

Controller D

Controller E

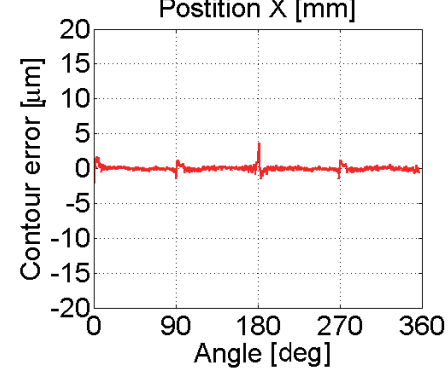

Controller F

Fig. 7. (Color online) Measured position and contour error at a feed rate of $3 \mathrm{~mm} / \mathrm{s}$ for controllers $\mathrm{D}, \mathrm{E}$, and $\mathrm{F}$.

Table 2

Contour errors in different friction compensation strategies at a feed rate of $3 \mathrm{~mm} / \mathrm{s}$.

\begin{tabular}{lcccc}
\hline Friction compensation technique & $\begin{array}{c}\text { Max contour } \\
\text { error }(\mu \mathrm{m})\end{array}$ & $\begin{array}{c}\text { Quadrant } \\
\text { glitch }(\mu \mathrm{m})\end{array}$ & $\begin{array}{c}\text { Root mean } \\
\text { square }(\mu \mathrm{m})\end{array}$ & $\begin{array}{c}\text { Standard } \\
\text { deviation }(\mu \mathrm{m})\end{array}$ \\
\hline $\begin{array}{l}\text { A. No friction compensation } \\
\text { B. Conventional friction }\end{array}$ & 15.72 & 15.72 & 7.73 & 11.21 \\
$\quad \begin{array}{l}\text { compensation } \\
\text { C. Proposed friction } \\
\quad \text { compensation }\end{array}$ & 7.36 & 7.36 & 1.14 & 1.56 \\
$\begin{array}{l}\text { D. Disturbance observer only } \\
\text { E. Disturbance observer + }\end{array}$ & 13.81 & $\mathbf{3 . 3 2}$ & 0.85 & 1.34 \\
$\quad \begin{array}{l}\text { conventional friction model } \\
\text { F. Disturbance observer }+\end{array}$ & 3.71 & 3.71 & 2.98 & 3.04 \\
$\quad$ & 5.43 & 5.43 & 0.43 & 0.58 \\
$\quad$ proposed friction model & & & 0.55 & 0.73
\end{tabular}

The benefit of the proposed nonlinear friction model is evident in the higher velocity region as shown in Table 3, which shows the average results of ten trials at a velocity of 9.5 $\mathrm{mm} / \mathrm{s}$. Figure 8 shows the contouring error results obtained by applying controllers D-F. In Table 3, we can see that the maximum contour errors in controllers B and $\mathrm{E}$ are greater 
Table 3

Contour errors in different friction compensation strategies at a feed rate of $9.5 \mathrm{~mm} / \mathrm{s}$.

\begin{tabular}{lcccc}
\hline Friction compensation technique & $\begin{array}{c}\text { Max contour } \\
\text { error }(\mu \mathrm{m})\end{array}$ & $\begin{array}{c}\text { Quadrant } \\
\text { glitch }(\mu \mathrm{m})\end{array}$ & $\begin{array}{c}\text { Root mean } \\
\text { square }(\mu \mathrm{m})\end{array}$ & $\begin{array}{c}\text { Standard } \\
\text { deviation }(\mu \mathrm{m})\end{array}$ \\
\hline $\begin{array}{l}\text { A. No friction compensation } \\
\text { B. Conventional friction }\end{array}$ & 12.74 & 12.74 & 6.88 & 9.73 \\
$\quad \begin{array}{l}\text { compensation } \\
\text { C. Proposed friction }\end{array}$ & 5.38 & $\mathbf{4 . 9 8}$ & 2.23 & 3.19 \\
$\quad \begin{array}{l}\text { compensation } \\
\text { D. Disturbance observer only }\end{array}$ & 16.72 & 2.99 & 1.29 & 1.81 \\
$\begin{array}{l}\text { E. Disturbance observer + } \\
\text { conventional friction model }\end{array}$ & 3.82 & 16.72 & 3.98 & 3.38 \\
F. Disturbance observer + & 1.56 & 1.56 & 1.01 & 1.38 \\
$\quad$ proposed friction model & & & 0.49 & 0.94 \\
\hline
\end{tabular}

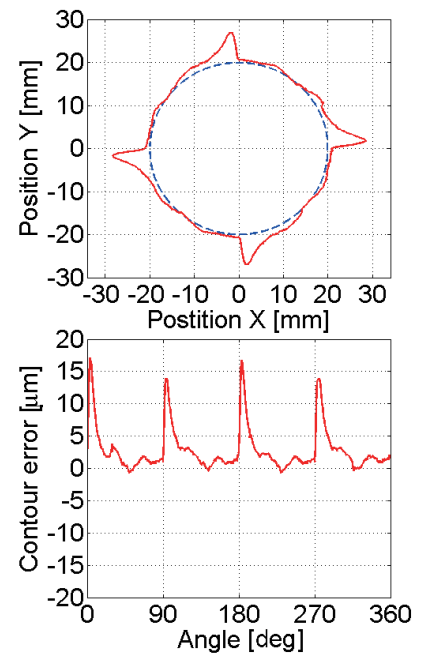

Controller D
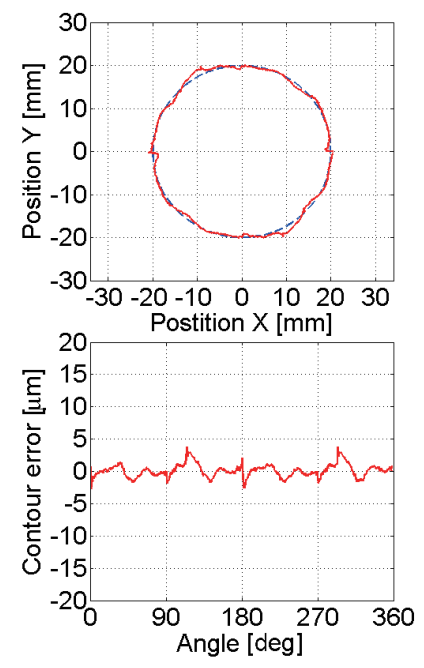

Controller E
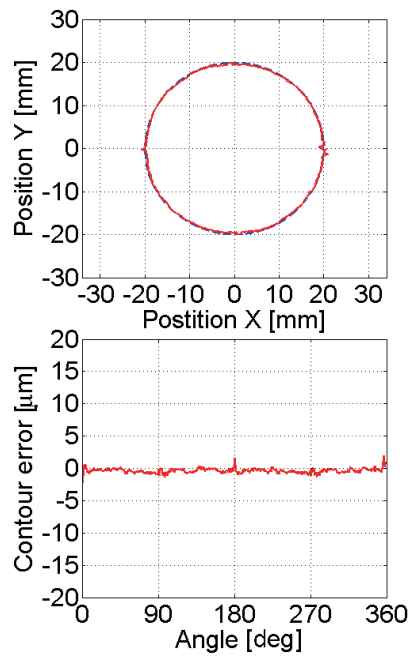

Controller F

Fig. 8. (Color online) Measured position and contour error at a feed rate of $9.5 \mathrm{~mm} / \mathrm{s}$ for controllers $\mathrm{D}$, $\mathrm{E}$, and $\mathrm{F}$.

than the maximum quadrant glitch, because nonlinear friction is dominant in the higher velocity region. Controller F clearly provides the best contour error performance, where the maximum contour error is reduced to only $1.56 \mu \mathrm{m}$. The root mean square value of the contour error and its standard deviation are also improved, with values of only 0.49 and $0.94 \mu \mathrm{m}$, respectively. 


\section{Conclusions}

The nonlinear friction properties in mechanical feed-drive systems were analyzed, and a new nonlinear static friction model was proposed for accurate motion control. Because the contour error is important in a machining application, a contouring controller design with feed-forward friction compensation based on the proposed nonlinear friction model and a disturbance observer was applied to solve a typical circular contouring control problem. Comparative experiments with several different friction compensations at both lower and higher motion velocities were conducted, and it was shown that the proposed controller was effective, particularly for higher velocity control applications, where the maximum contour error is reduced by $58 \%$ compared with that with a conventional static friction model. The contouring performance may be further improved by a combination of a dynamic friction model, such as the LuGre model, and the proposed nonlinear static friction model. This extension of this idea is left for future research.

\section{Acknowledgements}

This work was supported by JSPS KAKENHI grant number 24560131.

\section{References}

1 B. Armstrong-Hélouvry: Control of Machines with Friction (Kluwer Academic Publishers, 1991).

2 P. R. Dahl: Proc. 6th Annual Symp. Incremental Motion (Control System and Devices, 1977).

3 C. Canudas de Wit, H. Olsson, K. J. Astrom and P. Lischinsky: IEEE Trans. Autom. Control 40 (1995) 419.

4 J. Swevers, F. Al-Bender, C. Ganseman and T. Prajogo: IEEE Trans. Autom. Control 45 (2000) 675.

5 V. Lampaert, J. Swevers, F. Al-Bender, C. Ganseman and T. Prajogo: IEEE Trans. Autom. Control 47 (2002) 683.

6 F. Al-Bender, V. Lampaert and J. Swevers: IEEE Trans. Autom. Control 50 (2005) 1883.

7 B. P. Armstrong-Helouvry, P. Dupont and C. Canudas de Wit: Automatica 30 (1994) 1083.

8 C. Canudas de Wit and P. Lishinsky: Int. J. Adapt. Control Signal Process. 11 (1997) 65.

9 T. Tjahjowidodo, F. Al-Bender, H. Van Brussel and W. Symens: J. Sound Vib. 308 (2007) 632.

10 E. D. Tung, G. Anwar and M. Tomizuka: J. Dyn. Syst. Meas. Contr. 115 (1993) 279.

11 V. Lampaert, J. Swevers and F. Al-Bender: Proc. the 2004 American Control Conference (Boston, 2004) pp. 1121-1126.

12 K. Erkorkmaz and Y. Altintas: Int. J. Mach. Tools Manuf. 41 (2001) 1487.

13 Z. Jamaludin, H. Van Brussel and J. Swevers: Proc. 10th IEEE Int. Workshop Adv. (Motion Control (Trento, Italy, 2008) pp. 212-217.

14 Z. Jamaludin , H. V. Brussel and J. Swevers: IEEE Trans. Ind. Electron. 56 (2009) 3848.

15 Y. Li, Q. Zheng and L. Yang: Comput. Math. Appl. 64 (2012) 759.

16 J. A. Nelder and R. Mead: Comput. J. 7 (1965) 308.

17 N. Uchiyama, T. Nakamura and H. Yanagiuchi: Int. J. Mach. Tools Manuf. 49 (2009) 876.

18 G. T.-C. Chiu and M. Tomizuka: IEEE Trans. Control Syst. Technol. 9 (2001) 130. 
19 A. El Khalick M., N. Uchiyama and S. Sano: Int. J. Mach. Tools Manuf. 65 (2013) 8.

20 A. El Khalick M. and N. Uchiyama: Rob. Comput. Integr. Manuf. 29 (2013) 271.

21 N. Uchiyama, Y. Ogawa, A. El Khalick M., S. Sano and K. Yamazaki: 2013 European Control Conference (Zürich, Switzerland, 2013) 797.

22 N. Uchiyama, T. Nakamura and K. Yamazaki: Int. J. Automot. Technol. 3 (2009) 401.

23 A. El Khalick M. and N. Uchiyama: Mechatronics 21 (2011) 918.

24 A. El Khalick M. and N. Uchiyama: Rob. Comput. Integr. Manuf. 27 (2011) 802.

25 N. Uchiyama: Int. J. Mach. Tools Manuf. 49 (2009) 1204.

26 N. Uchiyama: Int. J. Mach. Tools Manuf. 48 (2008) 1234. 